\title{
Systemic Lupus Erythematosus Nephritis Class VI
}

National Cancer Institute

\section{Source}

National Cancer Institute. Systemic Lupus Erythematosus Nephritis Class VI. NCI

Thesaurus. Code C123122.

Systemic lupus erythematosus nephritis, with $90 \%$ or more of glomeruli globally sclerosed without residual activity. (Weening, Jan J. et al. (2004). The Classification of

Glomerulonephritis in Systemic Lupus Erythematosus Revisited. Journal of the American Society of Nephrology 15(2), 241-50.) 